\title{
A história das relações de gênero, histórias em construção
}

\section{História das relações de gênero.}

STEARNS, Peter $\mathrm{N}$.

Tradução de Mirna Pinsky.

São Paulo: Contexto, 2007. 251 p.

Apesar dos avanços consideráveis das últimas décadas, a história das relações de gênero ainda é um tema em construção. Por certo, já houve notável desenvolvimento do estudo da temática em pouco tempo, mas a consolidação desse campo de estudos ainda é muito recente. Como indica Carla Bassanezi Pinsky na apresentação dessa sugestiva obra de Peter Stearns, falar "em gênero é uma forma de enfatizar o caráter social e, portanto, histórico, das concepções baseadas nas percepções das diferenças sexuais" (p. 11, grifo da autora), profundamente arraigada num domínio masculino milenar, cuja dissolução total ainda não é um horizonte claramente perceptível em curto prazo. Não é por acaso, portanto, que esse livro trata "de interações entre definições de masculino e feminino, e dos papéis designados para homens e mulheres, de um lado, e dos encontros entre culturas diferentes, de outro", em especial, focalizando "essas interações, enfatiza dois tópicos mais agudos na pesquisa histórica das últimas décadas e os leva a se relacionar no campo da história mundial" (p. 15).

Por esse motivo, o autor propõe analisar o tema por meio de sua compreensão em diferentes lugares, culturas e temporalidades, de modo a inseri-lo no próprio movimento da história mundial. Para isso, não se limita apenas a demonstrar os padrões de sociabilidade e o estabelecimento de relações de gênero no Ocidente, mas tenta comparar esses padrões com outros do Oriente. Assim, preocupa-se em contar "uma série de histórias sobre as formas pelas quais os valores de gênero e os contatos culturais interagiram, como parte do material da história mundial, desde que os registros tornaramse suficientemente abundantes para explorar esse assunto" (p. 19). Também por isso o texto é mais panorâmico do que monográfico, sugere mais sínteses do que discussões exaustivas sobre cada tópico, cada época, cada lugar. Além disso, dá-se prioridade às análises comparativas, circunstanciando quais aproximações e distanciamentos se estabelecem de um lugar para o outro, de uma época para a outra.

Para efetuar essa discussão, o livro foi dividido em três partes complementares. $\mathrm{Na}$ primeira, aborda como nas civilizações clássicas (entre 1000 a.c. e 450) até o período pósclássico (entre 450 e 1450) foram estabelecidas as relações de gênero, a divisão e os atributos dos papéis sexuais, os contatos culturais e a organização de novos sistemas de convivência. $\mathrm{Na}$ segunda, adentra nos resultados da expansão europeia dos séculos XV ao XIX, avaliando as metamorfoses e as continuidades dos debates, das práticas e dos padrões de sociabilidade de homens e mulheres, no Ocidente e no Oriente, e seus contatos. Na terceira, propõe um estudo comparativo e, ao mesmo tempo, específico do século XX. Se, por um lado, as "grandes civilizações clássicas raramente tinham contato imediato entre si" ( $p$. 31), por outro, a partir do período pós-clássico elas se tornaram cada vez mais intensas, rápidas e complexas. Todavia, foi o "deslocamento da caça e coleta para a agricultura [que] pôs fim gradualmente a um sistema de considerável igualdade entre homens e mulheres" (p. 31) no período clássico e, em vista da qual, deu ensejo à constituição também gradual de um sistema patriarcal de dominação sociocultural, na qual a divisão de papéis sexuais na sociedade, atribuindo-se maior valoração aos masculinos, representaria uma parte de seu funcionamento, dado que a outra estaria na sua apreensão pelos indivíduos no tempo. Para ele,

\footnotetext{
O estabelecimento da civilização também fez avançar uma tendência a enfatizar as diferenças das instituições e formas culturais, destinadas a promover alguma unidade dentro do grupo e diferenciá-lo no exterior. Dessa forma, quase todas as civilizações desenvolveram um pronunciado sentido de quão diferentes eram dos 'outros' - a quem os gregos chamariam de bárbaros. Embora nem todas as civilizações tenham se expandido muito, houve uma tendência expansionista a fim de somar recursos e aliviar a pressão populacional (p. 28).
} 
O que resultaria em certo contato intercultural entre as civilizações, cujas relações tenderiam ainda, com a culminação de determinados padrões de expansionismo, a gerar a apropriação de modelos e sistemas de sociabilidade de uma para a outra, em certos casos, tornando mais híbridos os modelos tradicionais. Nesse ponto, duas questões devem ser levadas em consideração: a) primeiro, o estabelecimento de grupos pastoris nômades "que combinaram caça e agricultura transitória de corte e queimada"; e b) segundo, as próprias variações existentes no modelo patriarcal, de uma sociedade para outra, de um momento para o outro. Em vista disso também deve ser notado que nem toda sociedade agrícola do período clássico permitia a poligamia. De acordo com a força da religião no interior da sociedade, tornava-se maiores as variações sobre os papéis dos homens e das mulheres na sociedade. Um terceiro fator que tornaria peculiar o modelo das sociedades mediterrânicas seria sua relação com o racionalismo, que definia a função intelectual ao homem, enquanto as mulheres estariam ligadas aos traços sentimentais e afetivos. Mas as "influências da Grécia e do Mediterrâneo oriental também forneceram às mulheres romanas da classe alta novos modelos de ornamentos e luxo" (p. 57). Por sua vez,

O budismo ofereceu um quadro diferente ainda que complexo. A religião começou na Índia no século Vl a.e.c. [...] como uma rebelião parcial contra o sistema religioso que acabou se transformando no hinduísmo. O desagrado com a ênfase hindu na desigualdade era uma motivação-chave para a aceitação do budismo, e ainda que isso fosse particularmente dirigido contra o sistema de castas, tinha implicações nas relações de gênero também. Todos, do ponto de vista do budismo, independente do status social, participavam da essência divina, o que implicava, em última instância, alguma igualdade espiritual (p. 63).

Ao seguir de uma religião para a outra, de uma sociedade para a outra, destrinchando suas principais relações interculturais, ele vai indicando como tais contatos, mesmo que servidos para pluralizar certos valores, não conseguiam alterar princípios arraigados no tempo, como no caso dos muçulmanos. Nesse ínterim, a China também teria contribuído com a expansão de estruturas hierárquicas, por influenciar várias sociedades com esse modelo. Para ele,

A expansão da influência chinesa e confuciana atingiu as relações de gênero em grande parte da Ásia, embora nem todas as pessoas em contato com os chineses fossem afetadas. Os contatos demonstraram alguns dos aspectos imprevisíveis da reprodução de modelos. Os japoneses há muito respeitavam a superioridade chinesa, mas por certo tempo o empréstimo de costumes criou oportunidades surpreendentes para as mulheres, tanto por intermédio do budismo como por seu papel em assuntos culturais não chineses. As distinções óbvias entre as reações dos japoneses e a dos mongóis à influência cultural da China refletem diferentes posições de poder em relação aos chineses, assim como diferentes tradições relativas ao papel político das mulheres (p. 98).

Com os desdobramentos dos processos expansionistas da Europa, iniciados a partir do século $\mathrm{XV}$, os contatos interculturais com esse continente se tornaram mais intensos e complexos. Não sendo, evidentemente, uma via de mão única, porque a própria Europa esteve no centro do processo, distribuindo modelos, mas igualmente apreendendo outros. Para o caso das Américas,

Apesar da variedade [...] houve um fio comum [...] o contato com os europeus em geral piorou as condições das mulheres índias, em parte por causa das reações dos homens índios, mas principalmente porque os europeus tentaram reforçar a hierarquia de domínio masculino [...] [e] os europeus se declaravam muito chocados com as condições dos índios, e convictos, com freqüência, de estarem ajudando as mulheres. Visões conflitantes sobre trabalho e sexualidade figuravam com destaque nessa confusão, a qual, por sua vez, tendia a reforçar a propensão para a deterioração na condição das mulheres. As visões européias sobre gênero eram menos igualitárias do que as da maioria dos grupos indígenas, pelo menos até o final do século XIX (p. 11).

Na Rússia, entretanto, o efeito foi inverso, pois o "início da ocidentalização [...] fornece um caso claro e característico de impacto do contato cultural: a condição das mulheres [russas] melhorou" (p. 165). Os contatos do Ocidente com o Japão favoreceram também alterações nas relações de gênero de modo muito semelhante ao que ocorreu na Rússia, embora isso ocorresse durante um tempo muito menor do que o foi na Rússia. Nesse aspecto, "as reformas relativas a gênero em lugares como a Rússia e o Japão eram menos associadas com nacionalismo do que nas áreas coloniais; de fato, nacionalistas conservadores pareciam se sentir desconfortáveis com os ganhos femininos" (p. 181). Já no século XX, 
Os contatos culturais imprimiram mudanças na questão de gênero de duas maneiras fundamentais, embora sem subverter importantes continuidades do passado. Em primeiro lugar, os contatos internacionais se aceleraram e diversificaram. Em segundo lugar, alguns elementos novos e vitais foram introduzidos nas mensagens disponíveis a respeito dos papéis masculino e feminino (p. 186).

Assim, tendo em vista a expansão e a diversificação das religiões, deu-se o ensejo para o desenvolvimento do feminismo, do marxismo e do comunismo, que resultaram em forças culturais, com "impacto potencial em gênero" e sobre as discussões da questão, tendo em vista que suas respectivas recepções entre os países também foram amplamente diversificadas. Apenas como exemplo,

A China e a África oferecem dois casos importantes em que novos tipos de contatos internacionais se combinaram com pressões internas para produzir mudanças significativas. O caso chinês representa uma história mais completa, porque os novos contatos têm agido por todo um século e porque se entrelaçaram com um processo revolucionário fundamental. Mesmo assim, no entanto, em particular na zona rural, há sinais de traços remanescentes do patriarcado tradicional. Os exemplos africanos são mais experimentais, porque as pressões feministas internacionais são mais novas e interagem de forma complexa com os princípios nacionalistas. Muito mais do que na China, e além disso, os novos valores lutam com deteriorações econômicas, e as oportunidades de trabalho produtivo para as mulheres são com freqüência restringidas. Contudo, ocorreram grandes mudanças em ambos os casos, e talvez a mais importante seja a conscientização das mulheres, à medida que hábitos profundamente arraigados foram justapostos com uma variedade de sinalizações advindas de movimentos mais internacionais (p. 232).

Assim resumido o debate, verificou-se como o autor pôde discorrer sobre padrões e tendências, suas tipologias, seus impactos e mudanças ao longo do tempo. Nesse aspecto, a obra propõe um interessante painel sobre os momentos decisivos de fundação e apreensão de modelos de sociabilidade, atendo-se à expansão, dissolução e reformulação, geradas pelos contatos culturais que possibilitaram uma diversidade imensa de metamorfoses no interior de um ou vários modelos, em seu trato sobre as questões e as relações de gênero. Se no tempo e no espaço essas mudanças eram evidentes, a obra também demarca as várias formas de resistência que ocorreram, principalmente, nos modelos patriarcais que foram contrários à introdução de espaços para as mulheres e de maior igualdade entre homens e mulheres, na política ou no trabalho. Por todas as suas qualidades, a obra é um bom roteiro introdutório para a história mundial das relações de gênero.

Diogo da Silva Roiz

Universidade Estadual de Mato Grosso do Sul 